\title{
Regional differences in mortality from conditions amenable to medical intervention in The Netherlands: a comparison of four time periods
}

\author{
JOHAN P MACKENBACH, ANTON E KUNST, CASPAR W N LOOMAN, J DIK F \\ HABBEMA, AND PAUL J VAN DER MAAS \\ From the Department of Public Health and Social Medicine, Erasmus University Rotterdam, The Netherlands
}

SUMMARY In The Netherlands, as in many other countries, important geographical variation in mortality from conditions amenable to medical intervention exists. Associations with a number of simple medical care supply characteristics (general practitioner density, hospital bed density, and percentage of regional hospital beds located in university and small hospitals) are generally weak and inconsistent, both before and after controlling for possible confounding factors.

We explored one of the possible reasons for this lack of consistency, which is the time dependency of the relationship between medical care supply and avoidable mortality. A comparison of associations in four time periods (1950-54, 1960-64, 1970-74 and 1980-84) shows that the percentage of variance in regional mortality levels which can be "explained" by the medical care supply variables has changed over time. Although the patterns of change differ little from what one would expect on the basis of the time of introduction of medical care innovations, the exact nature of the associations is puzzling. Apart from some expected negative associations between mortality and the presence of university hospitals, we also found a few unexpected positive associations with general practitioner density.

Possible explanations for these findings are discussed, and it is concluded that further study is necessary to reveal the causes of a higher or lower mortality level for conditions considered to be amenable to medical intervention.

Monitoring the effectiveness of medical care services at population level is not the easiest task of health care policy makers. This activity requires the availability of outcome indicators that are precise, valid, and easy to collect. Unfortunately, there is no abundance of such indicators. $^{1}$

An English research group, building upon the work of Rutstein et al, ${ }^{2}$ has proposed the use of data on mortality from conditions which are considered to be largely amenable to medical intervention. ${ }^{3}$ Important geographical variation in mortality from such conditions has been demonstrated, both in England and Wales ${ }^{3}$ and in other countries of the European Community. ${ }^{4}$ The important question now is whether these mortality differences indeed reflect differences in medical care outcome, and if so, to which aspects of medical care delivery these outcome differences can be traced.

Two approaches to this question have been distinguished. First there are studies of the association between mortality, medical care characteristics, and potential confounding factors at an aggregate level; and in the second place there are in-depth studies of medical care and other factors in individual deaths from such causes. ${ }^{5}$ The latter approach, while probably being the most informative, presents many practical and methodological difficulties, and has not yet yielded any published results.

The former approach, being more feasible, has already produced some empirical findings. In England and Wales it was found that regional variation in morbidity, estimated from hospital admissions, notifications of infectious diseases, and cancer registry data, could only partly explain regional variation in mortality from conditions amenable to medical intervention. ${ }^{6}$ In another study, negative associations were found between mortality from such "avoidable" causes and some indicators of the level of resource provision (ie, a higher level of provision was associated with a lower level of mortality, as expected). It was noted that a correction for socio-economic differences would probably reduce the associations, since medical 
care supply and socio-economic conditions are strongly correlated in England and Wales. ${ }^{7}$ In Belgium, positive associations were found between mortality from the selected conditions and the level of medical care supply, after controlling for socioeconomic conditions. ${ }^{8}$ From France, weak negative associations have been reported, after controlling for socio-economic factors. ${ }^{9}$ In a comprehensive analysis of the relationship between medical care supply and mortality from these conditions in all countries of the European Community, we found associations to be generally weak and inconsistent. ${ }^{10}$

Mortality from conditions which have become amenable to medical intervention has generally decreased in the past decades. ${ }^{11} 12$ This suggests that decline in mortality partly reflects the introduction and diffusion of innovations in medical care. Associations between mortality levels and medical care supply characteristics at regional level could then be time dependent in the following way: (1) before a given cause of death becomes amenable to medical intervention, regional mortality levels are not associated with medical care supply characteristics; (2) during introduction and diffusion of the innovation(s) an association may emerge between regional mortality levels and one or more medical care supply characteristics if the latter determine the degree of application of the intervention at that particular moment in time; (3) after general diffusion, the association disappears again, due to the "law of diminishing returns" (a similar difference in degree of application produces a smaller difference in the level of mortality), and due to the fact that the prevailing degree of regional variation in medical care supply is not likely to bring about large enough differences in effort.

The analysis reported in this paper is an attempt to introduce this time dimension into the study of regional differences in mortality from "amenable" causes in The Netherlands. A presentation of the association with medical care supply characteristics in the early 1980s will be followed by an analysis of its evolution over time since the early 1950 s.

\section{Methods}

DATA

For four time periods (1950-54, 1960-64, 1970-74, 1980-84) numbers of deaths by age $(0,1-4,5-14, \ldots$ $85-94,95+)$, sex, region, and cause of death were extracted from a large computer file supplied by the Dutch Central Bureau of Statistics. Population numbers by age, sex, and region were also available from the Central Bureau of Statistics. The Dutch population register, from which deaths and population numbers are derived, and which is continuously kept up to date, is considered to be complete since the 19th century.

Although the mortality file permits a large number of regions to be distinguished, we amalgamated small contiguous regions so as to obtain a minimum population size of approximately 200000 throughout the period 1950-84. The resulting number of regions was 28 , with a minimum population size of 184000 in 1950 and 225000 in 1980, and with a median population size of 293000 in 1950 and 477000 in 1980.

The causes of death included in the analysis reported in this paper are presented in table 1 . International Classification of Disease (ICD) $\operatorname{codes}^{13}$ for the four revisions in force during the period 1950-84 were selected to achieve maximum correspondence between revisions. National trends in mortality from each of the causes so formed did not show important breaks between revisions, which suggests that the nosological content of these causes has not changed to a degree invalidating comparison over time. Two international studies of the quality of cause of death statistics have documented the comparatively high quality of Dutch certification and coding procedures. ${ }^{14} 15$

Table 1 Causes of death selected for analysis, grouped according to time of introduction of effective medical interventions within the study period (1950-1984)

\begin{tabular}{|c|c|c|c|c|}
\hline \multirow[b]{2}{*}{ Group } & \multirow[b]{2}{*}{ Cause of death } & \multirow[b]{2}{*}{ Age limits } & \multicolumn{2}{|c|}{ Total number of death } \\
\hline & & & $1950-54$ & $1980-84$ \\
\hline $\begin{array}{l}\text { I } \\
\text { "Early" }\end{array}$ & $\begin{array}{l}\text { Influenza and pneumonia } \\
\text { Tuberculosis } \\
\text { Other infectious diseases }\end{array}$ & $\begin{array}{l}0-74 \\
0-74 \\
0-74\end{array}$ & $\begin{array}{l}8973 \\
5867 \\
4967\end{array}$ & $\begin{array}{r}2233 \\
429 \\
1162\end{array}$ \\
\hline $\begin{array}{l}\text { II } \\
\text { "Early/ } \\
\text { late" }\end{array}$ & $\begin{array}{l}\text { Peptic ulcer } \\
\text { Three "surgical" conditions }{ }^{b} \\
\text { Prostate hyperplasia } \\
\text { Perinatal mortalityc } \\
\text { Rheumatic heart disease }\end{array}$ & $\begin{array}{l}0.74 \\
0.74 \\
0.74 \\
<1 \text { week } \\
0-74\end{array}$ & $\begin{array}{r}2197 \\
3646 \\
1365 \\
37898 \\
3905\end{array}$ & $\begin{array}{r}901 \\
1055 \\
194 \\
9089 \\
2563\end{array}$ \\
\hline $\begin{array}{l}\text { III } \\
\text { "Late" }\end{array}$ & $\begin{array}{l}\text { Congenital heart disease } \\
\text { Cerebrovascular disease } \\
\text { Hypertensive disease } \\
\text { Cancer of cervix uteri } \\
\text { Cancer at younger ages }\end{array}$ & $\begin{array}{ll}0 & -74 \\
0 & 74 \\
0 & 74 \\
0 & 74 \\
0 & -34\end{array}$ & $\begin{array}{r}2584 \\
21959 \\
4528 \\
1443 \\
3758\end{array}$ & $\begin{array}{r}1453 \\
18492 \\
1618 \\
1190 \\
3069\end{array}$ \\
\hline IV & Total mortality, all causes & $0-74$ & 240504 & 277536 \\
\hline
\end{tabular}

a Specific bacterial infections; viral diseases, commonly occurring in children; syphilis; infections of central nervous system; bacterial endocarditis; infections of respiratory system other than influenza and pneumonia; infections of skin; infections of locomotor system.

$\mathrm{b}$ Appendicitis; cholelithiasis/cystitis; abdominal hernia

c Stillbirths plus first week deaths.

The causes of death presented in table 1 form a selection from a larger number of conditions which can be considered amenable to medical intervention. Different authors have used slightly different selections of diseases, ${ }^{34891112}$ although all have been derived from Rutstein's original lists. ${ }^{2}$ From the 
conditions mentioned by Rutstein we selected those for which mortality has declined considerably in The Netherlands during (parts of) the period 1950-84 (Mackenback et al, submitted for publication). The analysis was further restricted to those causes for which the number of deaths was reasonably large during most of the study period. In order to reach sufficient numbers of deaths, some smaller causes were grouped together (a number of "Other infectious diseases", three "surgical" conditions, and all cancers in children and young adults, many of which have become manageable with the advances against Hodgkin's disease, leukemia, cancer of the testis, etc. ${ }^{216}$ ).

The resulting selection of diseases has been ordered in table 1 according to the time of introduction of medical care innovations. Chemotherapeutics and antibiotics, important in the reduction of infectious disease mortality, were introduced before 1950 . Although some effective interventions were available before 1950 for group II (peptic ulcer, "surgical" conditions, prostatic hyperplasia, perinatal mortality, rheumatic heart disease), important improvements and further significant innovations took place during the study period. Effective medical interventions for congenital heart disease, cerebrovascular and hypertensive disease, cancer of cervix uteri and cancer at younger ages only became available late in the study period.

Age limits were applied, because avoidability of death and quality of cause of death certification become increasingly questionable with age. In most cases we chose an age limit of 75 years, because up to 75 years mortality from the selected conditions declined rapidly during the study period, whereas in the higher age groups the declines were generally much less obvious.

The number of variables available for "explanation" of regional mortality patterns (table 2 ) is rather restricted, due to the fact that statistical information on a regional level has become more extensive only in recent years. Four medical care supply characteristics (two on the general level of supply, and two indicators of the level of technology in hospital care) were available for the whole study period. Three sociodemographic characteristics could be used to control for possible confounding variables: average income (as an indicator of socio-economic conditions), net immigration (which may indicate another aspect of socio-economic development, and perhaps also selection processes) and urbanisation (as an indicator of ways of living). The fertility rate (number of births per 1000 females 15-49 years), not mentioned in table 2, will be used as an additional control variable in the analysis of perinatal mortality. All data come from standard statistical sources, and although some minor changes in definition have occurred, comparability over time is satisfactory.

It is clear from table 2 that general practitioner density has decreased since 1950-54, and that hospital bed density has increased, whereas there has been a sharp reduction in the percentage of regional hospital beds located in small hospitals. The coefficient of variation of general practitioner density has decreased substantially, which indicates increasing geographic homogeneity. Average income (not corrected for inflation) has of course increased, but geographical heterogeneity has decreased.

Intercorrelations between medical care and other independent variables were generally modest. In $1950-54$ the only product-moment correlation $>0.50$ or $<-0.50$ was between the percentage of beds in small hospitals (SMALL) and degree of urbanisation (URB) $(-0 \cdot 57)$. In 1980-84 the only larger correlation was between hospital bed density (BED) and average income (INC) (0.50).

\section{ANALYSES}

For each cause of death (except perinatal mortality) and for each of the four periods, regional Standardised Mortality Ratios (SMRs) were calculated using national age and sex specific mortality rates of the same period as the standard. Regional perinatal mortality rates (still births and first week deaths, per

Table 2 The medical care supply characteristics and sociodemographic variables used in the analysis.

\begin{tabular}{|c|c|c|c|c|c|}
\hline & \multirow[b]{2}{*}{ Variable } & \multicolumn{2}{|c|}{$1950-54$} & \multicolumn{2}{|c|}{$1980-84$} \\
\hline & & Mean & $\begin{array}{l}\text { Coeff. of } \\
\text { variation }\end{array}$ & Mean & $\begin{array}{l}\text { Coeff. of } \\
\text { variation }\end{array}$ \\
\hline GP & Number of general practitioners (per 10000 population) & 4.48 & 26 & 3.81 & 7 \\
\hline BED & Number of hospital beds (per 1000 population) & 3.94 & 28 & $4 \cdot 57$ & 25 \\
\hline UNIV & Percentage of regional hospital beds located in University hospitals & $7 \cdot 14$ & 255 & $7 \cdot 33$ & 217 \\
\hline SMALL & Percentage of regional hospital beds located in small hospitals (ie, with less than 200 beds) & $46 \cdot 34$ & 69 & 12.07 & 105 \\
\hline INC & Mean income per capita (guilders $\times 1000$ ) & $1 \cdot 16$ & 16 & $12 \cdot 27$ & 11 \\
\hline MIGRA & Crude immigration rate (per 1000 population) & -2.66 & $0.45^{a}$ & 0.17 & $0 \cdot 33^{\mathrm{a}}$ \\
\hline URB & Degree of urbanisation $b$ & $25 \cdot 20$ & 108. & $28 \cdot 15$ & 78 \\
\hline
\end{tabular}

\footnotetext{
a Standard deviation
}

b Calculated as $(0.5 \mathrm{~A})+\mathrm{B}$, where $\mathrm{A}$ and $\mathrm{B}$ are the percentage of population living in cities with 50000100000 and more than 100000 inhabitants respectively 
1000 births) were expressed as a percentage of the national rate for the same period. For each cause of death and each period an overall $\chi^{2}$ test on heterogeneity between regions was carried out. ${ }^{17}$

In the regression analyses, the (natural) logarithm of the SMR (1n SMR) was used as the dependent variable so that, for example, an SMR of 0.50 is treated as having the same distance to 1.00 as an SMR of 2.00. In order to minimise the influence of chance fluctuations, regions were weighted according to the reciprocal of the variance of their SMRs, under the assumption that for these, mostly small, causes of death the variance of the error term in the regression is dominated by sampling variation. ${ }^{18}$ The variance of 1n SMR is equal to the reciprocal of the observed number of deaths. ${ }^{19}$ The calculations were carried out with the BMDP-package.

Spatial patterns, either of disease or of explanatory variables, often exhibit a simple gradient structure; eg, in The Netherlands there is a north-south gradient of mortality which can be followed through Belgium into Northern France. ${ }^{20}$ Such mortality gradients probably reflect otherwise unobservable environmental, social or cultural factors, ie, not medical care. The probability of two geographic gradients being non-orthogonal is high, so that a significant association between medical care supply and mortality, for example, might exist solely because of similar gradients. ${ }^{18}$

Variables describing geographic mortality gradients can thus be treated as potential confounders. Two series of multiple regression analyses were therefore carried out. In a first series only the independent variables mentioned in table 2 were entered. In a second series we added a set of variables which permit the measurement of geographic gradients in mortality: longitude, latitude, the squared values of longitude and latitude, and the cross-product. The estimates of the variables obtained with the regression model of the first series were quite robust against the addition of variables describing geographic gradients, so we shall only report the results of the more parsimonious model.

\section{Results}

Regional variation in mortality from the selected causes was mostly much larger than could be expected to occur by chance alone (table 3 ). Cancer in children/ young adults, where geographic heterogeneity never reached conventional levels of statistical significance, was the exception. This is not a small number problem (see table 1), but appears to be due to a lack of variation. As was to be expected, the coefficient of variation in general was larger with smaller numbers of deaths (compare tables 1 and 3). On the other hand, the categories, "other infectious diseases", "surgical" conditions, and cancer of cervix uteri, which were nearly equal in size in 1980-84, had differing degrees of regional variation, with "surgical" conditions clearly at the top.

Table 3 Regional variation in mortality from the selected causes: coefficient of variation of SMRs and significance level according to $\chi^{2}$ test for heterogeneity between regions.

\begin{tabular}{|c|c|c|c|c|c|}
\hline & & \multicolumn{4}{|c|}{$\begin{array}{l}\text { Coefficient of variation/significance } \\
\text { level }\end{array}$} \\
\hline & & $1950-54$ & $1960-64$ & $1970-74$ & $1980-8$ \\
\hline I & $\begin{array}{l}\text { Influenza and pneumonia } \\
\text { Tuberculosis } \\
\text { Other infectious diseases }\end{array}$ & $\begin{array}{l}21 \ddagger \\
23 \ddagger \\
10 t\end{array}$ & $\begin{array}{l}19 \pm \\
40 \pm \\
12^{*}\end{array}$ & $\begin{array}{l}20 t \\
25 \\
16 t\end{array}$ & $\begin{array}{l}16 \pm \\
37 \pm \\
16 t\end{array}$ \\
\hline II & $\begin{array}{l}\text { Peptic ulcer } \\
\text { Three "surgical" conditions } \\
\text { Prostate hyperplasia } \\
\text { Perinatal mortality } \\
\text { Rheumatic heart disease }\end{array}$ & $\begin{array}{r}22 \ddagger \\
18 \ddagger \\
23 \ddagger \\
9 \ddagger \\
20 \ddagger\end{array}$ & $\begin{array}{r}23 t \\
20 t \\
24 t \\
8 \ddagger \\
15 t\end{array}$ & $\begin{array}{r}14 \\
18 \ddagger \\
31 t \\
8 \ddagger \\
17 \ddagger\end{array}$ & $\begin{array}{r}28 t \\
26 t \\
44 \\
8 \ddagger \\
18 t\end{array}$ \\
\hline III & $\begin{array}{l}\text { Congenital heart disease } \\
\text { Cerebrovascular disease } \\
\text { Hypertensive disease } \\
\text { Cancer of cervix uteri } \\
\text { Cancer at younger ages }\end{array}$ & $\begin{array}{r}19 t \\
9 \ddagger \\
17 \pm \\
23 \pm \\
12\end{array}$ & $\begin{array}{l}13 t \\
12 \ddagger \\
25 t \\
21 \ddagger \\
13\end{array}$ & $\begin{array}{l}15^{*} \\
10 \pm \\
20 \pm \\
15^{*} \\
11\end{array}$ & $\begin{array}{l}19 * \\
10 \pm \\
15^{*} \\
20 \pm \\
15\end{array}$ \\
\hline IV & Total mortality, all causes & $6+$ & 67 & $5 \ddagger$ & $5 \ddagger$ \\
\hline
\end{tabular}

Significance levels: blank $p \geq 0.05 ;{ }^{*} p<0.05 ; \uparrow p<0.01 ; \ddagger p<0.001$

In the course of time, most of the causes of death have decreased in size. The accompanying increase in the relative importance of chance fluctuations will tend to inflate the coefficient of variation. It is remarkable, therefore, that for some of these causes the coefficient of variation had decreased or remained stable, eg, for influenza and pneumonia, perinatal mortality, and hypertensive disease. This suggests increasing geographic homogeneity of mortality from these causes.

Table 4 gives a first impression of the association between mortality and medical care supply characteristics in 1980-84, excluding causes for which no statistically significant geographic heterogeneity was found. The number of significant correlations was very small. The overall pattern was not very consistent, although all correlations attaining some degree of statistical significance were in the expected direction: negative for general practitioner density (GP) and percentage of regional hospital beds located in university hospitals (UNIV), positive for percentage of regional hospital beds located in small hospitals (SMALL).

Multiple regression analysis produces a slightly different picture of the associations between mortality and medical care supply characteristics in 1980-84 (table 5). The number of statistically significant associations was again very small. Some of these were 
Table 4 Correlation of mortality with medical care supply characteristics, 1980-84 (see table 2 for care classifications)

\begin{tabular}{|c|c|c|c|c|c|}
\hline & & \multicolumn{4}{|c|}{ Product moment correlations ${ }^{a}$} \\
\hline & & $G P$ & $B E D$ & UNIV & $S M A L L$ \\
\hline I & $\begin{array}{l}\text { Influenza and pneumonia } \\
\text { Tuberculosis } \\
\text { Other infectious diseases }\end{array}$ & $\begin{array}{l}0.13 \\
0.00 \\
0.07\end{array}$ & $\begin{array}{l}0 \cdot 10 \\
0 \cdot 30 \\
0 \cdot 22\end{array}$ & $\begin{array}{l}-0.00 \\
-0.11 \\
-0.03\end{array}$ & $\begin{array}{l}-0.07 \\
-0.13 \\
-0.22\end{array}$ \\
\hline II & $\begin{array}{l}\text { Peptic ulcer } \\
\text { Three "surgical" conditions } \\
\text { Perinatal mortality } \\
\text { Rheumatic heart disease }\end{array}$ & $\begin{array}{r}0.13 \\
-0.20 \\
0.20 \\
-0.45^{*}\end{array}$ & $\begin{array}{r}-0.02 \\
-0.26 \\
0.05 \\
-0.04\end{array}$ & $\begin{array}{c}0.09 \\
-0.53^{*} \\
-0.28 \\
0.06\end{array}$ & $\begin{array}{l}0.17 \\
0.35^{\boldsymbol{r}} \\
-0.16 \\
-0.05\end{array}$ \\
\hline III & $\begin{array}{l}\text { Congenital heart disease } \\
\text { Cerebrovascular disease } \\
\text { Hypertensive disease } \\
\text { Cancer of cervix uteri }\end{array}$ & $\begin{array}{r}0.16 \\
-0.21 \\
0.06 \\
0.18\end{array}$ & $\begin{array}{r}-0.06 \\
-0.14 \\
0.25 \\
0.11\end{array}$ & $\begin{array}{l}-0.32 r \\
-0.26 \\
-0.25 \\
0.04\end{array}$ & $\begin{array}{c}0.09 \\
-0.31 \\
0.34^{\sigma} \\
0.28\end{array}$ \\
\hline IV & Total mortality, all causes & 0.09 & 0.01 & 0.07 & -0.26 \\
\hline
\end{tabular}

Significance levels (two-sided test): ${ }^{\top} \mathrm{p}<0.10 ;{ }^{*} \mathrm{p}<0.05$

a Unweighted correlations $(n=28)$

in the expected direction, but others were not, eg, between mortality from tuberculosis and hospital bed density (positive), and between cerebrovascular disease mortality and percentage of beds in small hospitals (negative).

Table 5 Regression of mortality on medical care supply characteristics, controlling for sociodemographic variables, 1980-1984' (see table 2 for care classifications)

\begin{tabular}{|c|c|c|c|c|c|}
\hline & \multicolumn{4}{|c|}{ Regression coefficient } \\
\hline & & $G P$ & $B E D$ & UNIV & $S M A L L$ \\
\hline III & $\begin{array}{l}\text { Influenza and pneumonia } \\
\text { Tuberculosis } \\
\text { Other infectious diseases }\end{array}$ & $\begin{array}{r}0.177 \\
-0.103 \\
-0.092\end{array}$ & $\begin{array}{l}0.011 \\
0.253^{*} \\
0.023\end{array}$ & $\begin{array}{l}-0.0027 \\
-0.0076 \\
-0.0020\end{array}$ & $\begin{array}{l}-0.0011 \\
-0.0076 \\
-0.0023\end{array}$ \\
\hline II & $\begin{array}{l}\text { Peptic ulcer } \\
\text { Three "surgical" conditions } \\
\text { Perinatal mortality } \\
\text { Rheumatic heart disease }\end{array}$ & $\begin{array}{r}0.224 \\
-0.151 \\
0.045 \\
-0.337\end{array}$ & $\begin{array}{r}-0.004 \\
0.012 \\
-0.017 \\
0.063\end{array}$ & $\begin{array}{r}-0.0087^{*} \\
-0.0014 \\
0.0008\end{array}$ & $\begin{array}{l}0.0028 \\
0.0048 \\
0.0003 \\
0.0019\end{array}$ \\
\hline III & $\begin{array}{l}\text { Congenital heart disease } \\
\text { Cerebrovascular disease } \\
\text { Hypertensive disease } \\
\text { Cancer of cervix uteri }\end{array}$ & $\begin{array}{r}-0.036 \\
-0.037 \\
-0.080 \\
0.132\end{array}$ & $\begin{array}{r}-0.003 \\
0.017 \\
0.025 \\
-0.029\end{array}$ & $\begin{array}{c}-0.0047 \\
-0.0040^{*} \\
-0.0027 \\
0.0001\end{array}$ & $\begin{array}{r}-0.0018 \\
-0.0042^{*} \\
0.0043 \\
0.0049\end{array}$ \\
\hline IV & Total mortality, all causes & 0.005 & 0.006 & -0.0005 & -0.0010 \\
\hline
\end{tabular}

Significance levels (two-sided test): ${ }^{\top} p<0.10 ; * p<0.05$.

a Multiple regression model containing four medical care variables and three socio-demographic variables. Dependent variable is In SMR, weighted with the observed number of deaths. When no value is mentioned in the table, the variable has not been entered into the regression model because the tolerance level was exceeded.

In order to investigate whether the associations between mortality from the selected causes and medical care supply characteristics are time dependent, the results of regression analyses for each of the four time periods were compared. For each cause of death the figure shows the (additional) percentage of variance explained by the four medical care supply variables, after controlling for sociodemographic factors. We expect relatively important contributions of medical care variables in 1950-54 and 1960-64 for group I, and in 1970-74 and $1980-84$ for group III. For group II, it is more difficult to specify such a hypothesis.

The findings show that the associations were indeed time dependent, but that the timing of changes only partly conformed to our expectations. In group I, medical care variables contributed little in 1950-54, and a bit more in 1960-64. The largest contribution was for Tuberculosis in 1980-84.

In group III, the contribution of medical care supply characteristics to the explanation of regional mortality patterns was relatively small in 1950-54 and 1960-64 for all disease categories except Cerebrovascular disease. An important association emerges in 1970-74 for Congenital heart disease. For Cerebrovascular disease the contribution of medical care variables increased towards the end of the study period.

In group II, changes in the association with medical care variables can be seen for several diseases. For "Surgical" conditions the additional percentage of variance explained was larger in 1970-74 and 1980-84. For Prostate hyperplasia the contribution was relatively large in 1950-54, then decreased, and finally increased again. For Perinatal mortality, a larger contribution of medical care supply characteristics emerged temporarily in 1970-74.

For total mortality the additional percentage of variance explained by medical care variables after controlling for sociodemographic factors was uniformly small.

Table 6 presents estimates of the regression coefficients for those combinations of time periods and causes of death that were characterised by relatively high additional percentages of variance explained $(\geq 20 \%)$ by medical care variables. General practitioner density had many statistically significant associations with mortality, but many of these were not in the expected direction. The negative associations between the percentage of regional hospital beds located in University hospitals are in line with our expectations.

\section{Discussion}

Although in comparison with other European countries The Netherlands have rather low levels of mortality from conditions amenable to medical intervention, ${ }^{4}$ there is nevertheless important geographical variation in mortality from these conditions within the country. Our analysis of the relationship between mortality from such conditions and a number of simple medical care supply characteristics revealed only a small number of possibly meaningful relationships. 


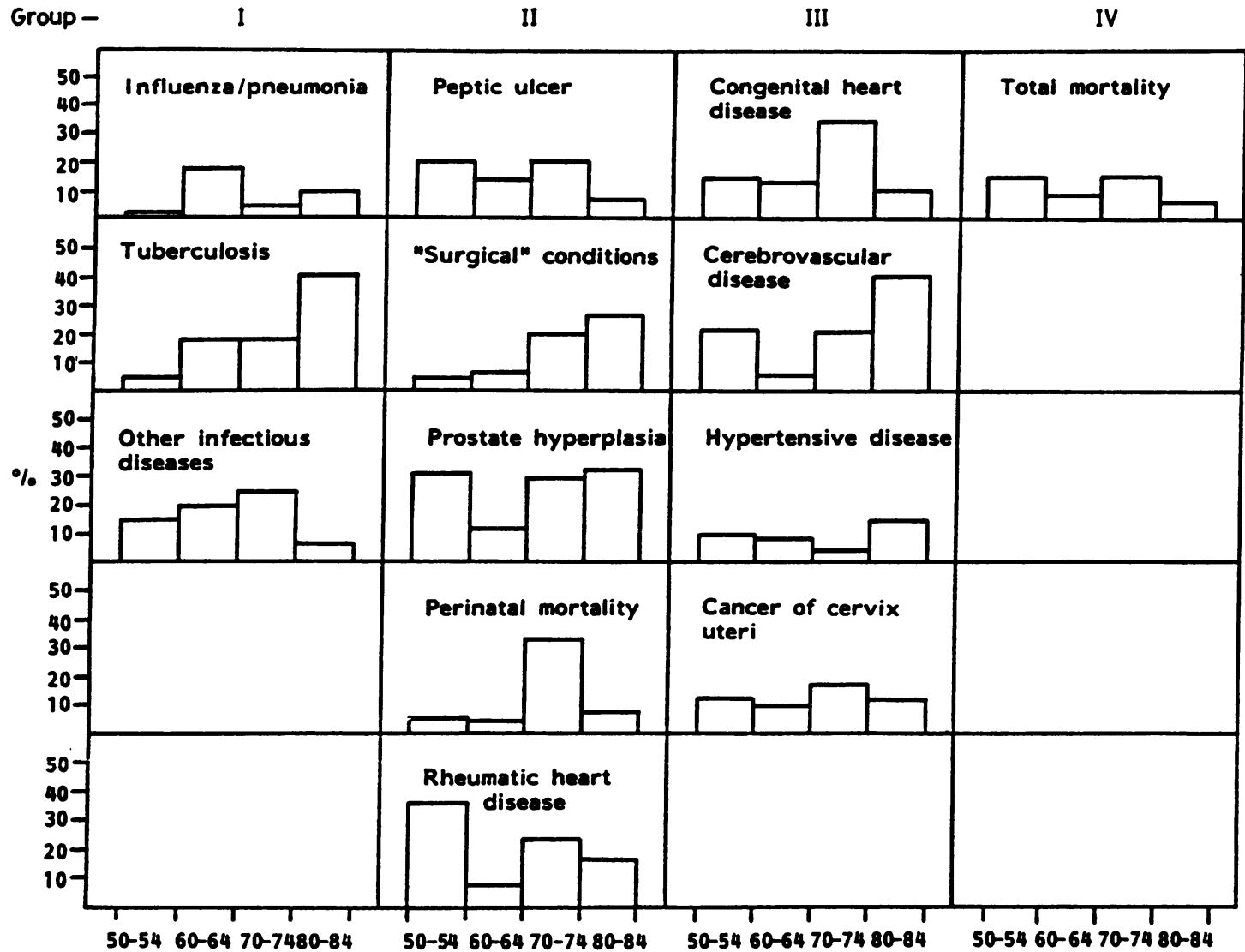

Figure. Additional percentage of variance explained by medical care supply characteristics, after controlling for sociodemographic variables.

Table 6 Regression of mortality on medical care supply characteristics, controlling for sociodemographic variables, for a few selected causes of death and time periods ${ }^{a}$

\begin{tabular}{|c|c|c|c|c|c|}
\hline & & \multicolumn{4}{|c|}{ Regression coefficient } \\
\hline & & $G P$ & $B E D$ & UNIV & $S M A L L$ \\
\hline I & $\begin{array}{l}\text { Tuberculosis }(1980-84) \\
\text { Other infectious diseases }(1960-64) \\
(1970-74)\end{array}$ & $\begin{array}{c}-0.103 \\
0.039 \\
0.250^{*}\end{array}$ & $\begin{array}{l}0.253^{*} \\
0.020 \\
0.007\end{array}$ & $\begin{array}{l}-0.0076 \\
-0.0005 \\
-0.0019\end{array}$ & $\begin{array}{l}-0.0076 \\
-0.0008 \\
-0.0007\end{array}$ \\
\hline II & $\begin{array}{r}\text { Peptic ulcer }(1950-54) \\
\quad(1970-74) \\
\text { "Surgical" conditions }(1970-74) \\
(1980-84) \\
\text { Prostate hyperplasia }(1950-54) \\
(1970-74) \\
(1980-84) \\
\text { Perinatal mortality }(1970-74) \\
\text { Rheumatic heart disease }(1950-54) \\
(1970-74)\end{array}$ & $\begin{array}{r}0.034 \\
-0.045 \\
0.038 \\
-0.151 \\
0.046 \\
0.464^{*} \\
-0.700^{*} \\
0.134^{*} \\
-0.100^{*} \\
-0.288^{*}\end{array}$ & $\begin{array}{r}0.064 \\
0.048 \\
0.069 \\
0.012 \\
0.151^{*} \\
0.006 \\
-0.037 \\
-0.004 \\
-0.039 \\
0.064\end{array}$ & $\begin{array}{c}0.0015 \\
-0.0037 \\
-0.0034 \\
-0.0087^{*} \\
-0.0008 \\
\\
-0.0061 \\
-0.0026^{*} \\
0.0031 \\
-0.0010\end{array}$ & $\begin{array}{r}0.0037^{*} \\
-0.0008 \\
0.0039 \\
0.0048 \\
0.0024 \\
0.0029 \\
0.0058 \\
-0.0004 \\
-0.0024 \\
0.0002\end{array}$ \\
\hline III & $\begin{array}{r}\text { Congenital heart disease }(1970-74) \\
\text { Cerebrovascular disease }(1950-54) \\
(1970-74) \\
(1980-84)\end{array}$ & $\begin{array}{r}0.022 * \\
0.097 \\
-0.087 \\
-0.037\end{array}$ & $\begin{array}{l}0.010 \\
0.016 \\
0.027 \\
0.017\end{array}$ & $\begin{array}{r}-0.0018 \\
0.0005 \\
-0.0020^{\star} \\
-0.0040^{*}\end{array}$ & $\begin{array}{l}-0.0006 \\
-0.0012 \\
-0.0006 \\
-0.0042^{*}\end{array}$ \\
\hline
\end{tabular}

Significance levels (two-sided test): $\bullet p<0 \cdot 10 ; * p<0.05$

${ }^{a}$ See note a, table 5 . 
In 1980-84, the presence of a University hospital appeared to be associated with lower mortality levels for "Surgical" conditions and Cerebrovascular disease. Further study is necessary to reveal whether or not this is a spurious association, occurring by chance (multiple significance testing as in tables 4 and 5 is likely to produce a small number of statistically significant coefficients, even in the absence of any real associations), or due to insufficient control of confounding variables.

A comparison of regression results over time shows that the percentage of variance in regional mortality levels which can be "explained" by medical care supply variables is rather time dependent. Associations emerge and disappear, and although the timing of these changes is not very different from what might be expected, the exact nature of the associations is sometimes puzzling. A large number of general practitioners per 10000 population (which is equivalent to smaller average list size of general practitioners) was associated repeatedly with higher mortality from conditions amenable to medical intervention. Again this could be a spurious association, but it could also indicate that improvements in medical care reach the average patient with these conditions later in regions where a large proportion of patient care is being delivered by general practitioners.

On the whole, however, the association between mortality from conditions amenable to medical intervention and medical care supply can be summarised as weak and inconsistent, as has been found in other studies. ${ }^{8-10}$ What are the implications of this finding? First of all, it is important to note that the medical care variables available for analysis were crude supply characteristics. The way in which this supply is organised, made to conform to quality standards, and made accessible to the population could well be more important in the prevention of deaths from "amenable" causes than the level of the supply. This implies that differences in mortality from these conditions may still be valid indicators of medical care outcome, and also that further validation studies at an aggregate level should use indicators of more specific aspects of medical care delivery.

Having said this, the absence of a clear pattern of associations between levels of medical care supply and mortality from conditions amenable to medical intervention remains an intriguing finding. Are we to conclude that regional differences in medical care supply, which are important from a financial point of view, have no consequence for at least one outcome indicator, mortality? Or could real differences in mortality outcome have gone undetected in our analysis?

Real differences in mortality due to differences in supply could have gone undetected if there has been serious misclassification of causes of death. Systematic regional differences in certification of causes of death have not been found in the very few studies that have looked into this. ${ }^{21} 22$ Even non-differential misclassification, however, may bias associations between cause specific mortality and other regional characteristics towards the null. ${ }^{23}$ On the other hand, given the fact that cause specific mortality patterns have been shown to reflect the geographical distribution of a number of risk factors ${ }^{24}$ it is unclear why they would be unable to reflect differences in outcome of medical care. For most of the conditions analysed in this paper, the effects of medical intervention on mortality do not have very long lag times. Migration is thus unlikely to be responsible for the lack of associations between medical care supply and mortality. Rheumatic heart disease may be an exception, so far as prevention by treatment of streptococcal infections is concerned. Finally, if mortality patterns for the selected causes of death are dominated by spontaneous differences in incidence, effects of medical care on mortality may be difficult to detect. The question then is whether the sociodemographic variables treated as confounders have adequately controlled for such incidence differences. The fact that a regression model including geographic variables produced largely the same results (see methods section) does not, however, suggest that inadequate control for incidence differences explains the lack of meaningful associations.

The most likely explanation is that, within the prevailing range of variation, regional differences in medical care supply in The Netherlands do not have serious effects on at least one outcome indicator, mortality. We suspect that, at the levels observed in most industrialised countries, an increase in supply of hospital beds and physicians mainly leads to an increase in "discretionary" procedures, and not to an increase in procedures for life threatening conditions, which are treated anyway. ${ }^{25}$ Whether this is a comforting or a disturbing thought is difficult to say.

The study reported in this paper was supported by a grant from the Ministry of Welfare, Public Health and Culture. The mortality data were supplied by the Central Bureau of Statistics, in the framework of a special collaboration agreement. The data on general practitioners were kindly made available by Dr P P Groenewegen, Netherlands Institute of Primary Health Care (NIVEL).

Address for correspondence and reprints: $\operatorname{Dr} \mathbf{J} \mathbf{P}$ Mackenbach, Department of Public Health and Social Medicine, Erasmus University Rotterdam, PO Box 1738, 3000 DR Rotterdam, The Netherlands. 


\section{References}

${ }^{1}$ Mackenbach JP. Health care policy and regional epidemiology: international comparisons and a casestudy for The Netherlands. Soc Sci Med 1987; 24: 247-53.

${ }^{2}$ Rutstein DD, Berenberg W, Chalmers TC et al. Measuring the quality of medical care: second revision of tables of indexes. $N$ Engl J Med 1980; 302: 1146, and 294: 582-88.

${ }^{3}$ Charlton JRH, Silver RM, Hartley RM et al. Geographical variation in mortality from conditions amenable to medical intervention in England and Wales. Lancet 1983; i: 691-6.

${ }^{4}$ EC Concerted Action Project "Health Services and Avoidable Mortality". EC atlas of avoidable death. Oxford: Oxford University Press, 1988.

${ }^{5}$ Charlton JRH, Bauer RL, Lakhani AZ. Outcome measures for district and regional health care planners. Community Med 1984; 6: 306-15.

${ }^{6}$ Bauer RL, Charlton JRH. Area variation in mortality from diseases amenable to medical variation: the contribution of differences in morbidity. Int $J$ Epidemiol 1986; 15: 407-11.

${ }^{7}$ Department of Community Medicine (UMDS, St. Thomas's Hospital, London, UK), Medical intervention and the avoidability of death, Progress report, December 1983.

${ }^{8}$ Humblet PC, Lagasse R, Moens GFG et al. La mortalité évitable en Belgique. Soc Sci Med 1987; 25: 485-93.

9 Jougla E, Ducimétière P, Bouvier-Colle MH, Hatton F. Relation entre le niveau de développement du système de soins et le niveau de la mortalité "évitable" selon les départements Français. Rev Epidémiol Santé Publ 1987; 35: 365-77.

${ }^{10}$ Kunst AE, Looman CWN, Mackenbach JP. Medical care and regional mortality differences within the countries of the European Community. Eur J Population 1988, in press.

${ }^{11}$ Charlton JRH, Velez R. Some international comparisons of mortality amenable to medical intervention. Br Med J 1986; 292: 295-301.

12 Poikolainen K, Eskola J. The effect of health services on mortality: decline in death rates from amenable and non-amenable causes in Finland, 1969-1981. Lancet 1986; i: 199-202.
${ }^{13}$ World Health Organization. International statistical classification of diseases, injuries, and causes of death (9th revision). Geneva: WHO, 1975.

14 Anonymous. The accuracy and comparability of death statistics. WHO chronicle 1967; 21: 11-7.

${ }^{15}$ Mackenbach JP, Duijne WMJ van, Kelson MC. Certification and coding of two causes of death in The Netherlands and other countries of the E.C.J Epidemiol Community Health 1987; 41: 156-60.

${ }^{16}$ Hammond D. Progress in the study, treatment and cure of the cancers of children. In: Burchenal JH, Oettgen HF, eds. Cancer-achievements, challenges and prospects for the 1980's. New York: Grune \& Stratton, 1981 .

${ }^{17} \mathrm{Gail}$ M. The analysis of heterogeneity for indirect standardised mortality ratios. J R Statist Soc A 1978; 141: 224-34.

${ }^{18}$ Pocock SJ, Cook DG, Shaper AG. Analysing geographic variation in cardiovascular mortality: methods and results. J R Statist Soc A 1982: 145: 313-41.

${ }^{19}$ Pocock SJ, Cook DG, Beresford SAA. Regression of area mortality rates on explanatory variables: what weighting is appropriate? Appl Stat 1981; 30: 286-96.

${ }^{20}$ van Poppel F. Regional mortality differences in Western Europe. Tijdschr Soc Geneeskd 1981; 59: 170-8 (in Dutch).

${ }^{21}$ Nefzger MD, Acheson RM, Heyman A. Mortality from stroke among US veterans in Georgia and 5 western states. J Chron Dis 1973; 26: 393-446.

${ }^{22}$ Diehl AK, Gau DW. Death certification by British doctors: a demographic analysis. J Epidemiol Community Health 1982; 36: 146-9.

${ }^{23}$ Kleinbaum DG, Kupper LL, Morgenstern H. Epidemiologic research - principles and quantitative methods. London: Lifetime Learning Publications, 1982.

${ }^{24}$ Rosén M. Epidemiology in planning for health. Umea (Sweden): Department of Social Medicine, Epidemiology and Health Care Research of the University of Umea, 1987.

${ }^{25}$ Wennberg JE, Freeman JL, Culp WJ. Are hospital services rationed in New Haven or over-utilised in Boston? Lancet 1987; i: 1185-8.

Accepted for publication June 1988 